\section{Relações Públicas e micropolítica: um estudo comparativo de seus processos e programas}

Este artigo integra o Projeto de Pesquisa intitulado:U ma Teoria para 0 Ensino e a Prática da A tividade de Relações Públicas, tendo como órgãos financiadores a PUCRS para o professorpesquisador, e o CN Pq para a bolsista de iniciação científica.

\section{Resumo}

ESTE ARTIGO CONTÉM um estudo comparativo entre os processos e programas de Relações Públicas e micropolítica, aprofundando a teoria da gestão da função organizacional política para explicar a atividadedeRelações Públicas. Dissertasobreo designativo política e relação de poder. Reduz a angular da macropolítica paraa micropolítica. Integra os conceitosdemicropolíticaexistentesnasáreas da educação e da ciência política. Explana queaorganizaçãoé, por excelência, umâmbito político. Realiza o estudo comparativo demonstrando a coincidência entre os processos e programas de micropolítica e Relações Públicas. Por fim, enfoca a comunicação como instrumento do exercício depoder, sendo este a essência e a comunicação, a aparência.

\section{Introdução}

É comum escutar-se na comunidade de Relações Públicas, pelo menos no Brasil, que a atividade, portanto o profissional e a profissão, de Relações Públicas não é valorizada pelos empresários e governantes. Estapremissaécitada, indiscriminadamente, nãosomente por aquelesque, tendo concluído seus cursos universitários, se encontram marginais ao mercado de trabalho, mas, também, por aqueles que recebem baixos salários. Idemaosqueencontram dificuldades de promoção e, ainda, pelos quejá tiveram a amarga experiência de serem despedidos, uma ou mais vezes, sob a justificativa de que 
a empresa tinha quereduzir custos. Inclua-se também os inúmeros profissionais bem situados na atividade e que tiveram que enfrentarlongo processo decarreiraatéatingir o êxito.

Seeste fenômeno éreal idade, por queestaria ocorrendo ?

A análise dos fatos permite dizer que, excluindo:

1 os problemas de mercado de trabalho, comuns a todas as profissões, em face das inúmeras variáveis; onde a oferta de profissionais está maior que a demanda;

2 o fato de que a maior parte das organizaçõesnãopossui explícitossuamissão e seus objetivos a longo prazo, logo se apresentam sem visão estratégica, característica essencial para a preocupação com a administração doseu relacionamento político;

3 o entorno não exigente onde se situam as empresas brasileiras, onde a maioria do povonãoépolitizada, ou seja, éapenassujeito, jamais cidadã, e, portanto, não faz valer seus interesses e direitos; não pressiona as organizações irresponsáveis;

4 a quase inexistente denúncia das organizações sem responsabilidade social não cumprindo sua mi ssão ad equadamentepor meio de um jornalismo investigativo efetivo;

5 um número grande de empresas com um único proprietário sem preocupações quanto à existência a longo prazo de sua organização;

6 a existência de grande número de empresas estatais, ou mesmo privadas, como monopólio no seu ramo de atuação;

7 osistemajudiciáriomoroso, dificultando a execução da justiça em benefício dos prejudicados;
8 a comunidade do direito ainda estar penetrando no filão de causas que o Código deDefesa do Consumidor podeoportunizar;

9 a agropecuária na dependência exclusiva do governo público, não tendo que se preocupar comoutrosagentescominfluência, exceção, tal vez, comos cartéis internacionais, quando chega a hora de exportar.

Há, certamente, al guns problemasespecíficos na teoria, no ensino ena prática da atividade de Relações Públicas.

Neste ângulo, penso que a causa original do problemaespecíficoencontra-se, basicamente, no paradigma de como a comunidade de Relações Públicas está entendendo, oferecendo e operacionalizando a atividade. A comunidade aglutina os crentes da compreensão mútua e do mito da comunicação. Porém, pior ainda, executa tarefas sob visão restrita, produzindo eventos e peças que qualquer pessoacomhabilidadessociaispode produzir sem a necessidade de um curso universitário e cujos resultados são mais circunstanciais do que estrategicamente alinhavados. Oferece-se uma atividade necessária às organizações, porém promovendo-a com argumentos equivocados e colocando-a em prática, com resultados ineficazes para o problema real das organizações.

Por umdesviohistórico, poisapesar do ensino da atividadeter brotado, no Brasil, naárea da administração, foi florescer na esfera da Comunicação Social, está-se oferecendo e praticando a "compreensão mútua", a comunicação, a promoção e, principalmente, os benefíciossociais. Está-sepreocupadomais com a ética da ação organizacional, com a responsabilidadesocial do quecomo retorno dosjustos resultados econômico-financeiro e políticos, por vezes prejudicados em razão de conflitos e crise entre a organização e seus públicos. Porém, se está inconsciente de que se está sendo antiético, pois a ação reside na superficialidadedodiscurso, pouco, ou quase 
nada, buscando a ação comunicativa. A pesar de que já brota a consciência de que não se pode situar exclusivamente na formação de imagem sem qualquer vínculo com a realidade. $O$ posicionamento deve procurar umequilíbrio entreesses doisextremos. Além do que, enfocar somente a imagem é permanecer no primeiro degrau de uma escada cujo plataforma mais elevada é a autonomia da organização.

Uma das variáveis da causa, historicamente estabel ecida, radica-senaadoção da definição conceitual deRelações Públicas, estabelecida pela Associação Brasileira de Relações Públicas(ABRP), desdeseusprimórdios, cópia literal dadefinição doInstituto Inglês, mantida e divulgada, até hoje, sem nenhuma crítica objetivo-científica dos profissionais e dos acadêmicos da área.

Essadefiniçãotemconstruídodoisproblemas:

(1) Coloca a atividade exclusivamente ao foco da comunicação, sem delimitar os significados deste conceito, encobrindo os aspectos da relação de poder no sistema organização-públicos e, portanto, esquecendo-sedascausasquelevamaosconflitostanto internos como ao entorno das organizações.

(2) Tem feito com que a atividade seja percebida e atue exclusivamente como operativo-tarefeira. A comunidade de Relações Públicas tem atuado, profissional e timidamente, quando muito, nas "batal has das idéias" (Metáfora de Pirie, 1988, p. 37) e deixado de lado o assessoramento na implementação de políticas organizacionais.

Ora, assim posicionada, tem seu mercado de trabalho prejudicado, pois aos empresários, aos governantes eaos dirigentes dequal quer tipo de organização interessa escutar outras justificativas e verificar resultados que justifiquemseu dispêndio detempoedinheiro com a contratação de um profissional e com todos os programas de ação que Ihe serão propostos.
Se tudo isto ocorre há quase três décadas no Brasil, considerando oano no qual a profissão passou a integrar o currículo do curso universitário, é óbvio que se deve realizar uma análise da situação e, possivelmente, propor um novo quadro de referência para o ensino e para a prática da atividade.

Essenovo enquadramento do queseentende e de como se pratica Relações Públicas deve conter, intrinsecamente, uma teoria e, por conseguinte, uma definição da atividade de Relações Públicas, integrando aspectos conceituais com operacionais, que venha a:

1 apresentar idéia clara e objetiva de sua missão, caracterizando resultados culturais, econômicos, políticoseéticos paraasociedade;

2 explicitar, ao dirigente organizacional, a ação do profissional, a fim de que possa exigir deste o seu papel real, contratando-o como estrategista com soluções políticas para os conflitos da organização com os agentes com influência e evitando posicioná-lo, exclusivamente, como executor de instrumentos de informação e persuasão ou, pior ainda, como simples promotor de produto;

3 caracterizar a prática da atividade, permitindo ao profissional, ao chegar na organização, dizer ao poder central que está ali para ajudá-lo a ganhar tempo e dinheiro, impedindo que agentes com influência prejudiquem a orientação e o ritmo da busca da missão e dos objetivos da organização;

4 facilitar o processo ensino-aprendizagem da atividade por oferecer, a todos os envolvidos com o mesmo, um rationale comum;

5 ser clara para aqueles que administram o currículo, a fim desaber imprimir a filosofia do curso, estruturar, economicamente, a relação de disciplinas e a sua sinergia.

6 promover o entendimento no corpo docente por meio deenfoques adequados das 
suas diversas disciplinas, evitando ausência ou redundância de assuntos;

7 caracterizar as práticas didáticas, fazendo do curso uma preparação para o mercado, jamais, somente, uma orientação para o mercado;

8 desvelar a bibliografia complementar, em especial das Ciências Sociais que dão suporteàcompreensão detodasasdimensões do fenômeno da estrutura - componentes e dinâmica - do sistema organização-públicos;

9 orientar o professor em uma linha de raciocínio para que não misture Relações Públicas com outras atividades dos outros ramos da comunicação social e da administração.

10 orientar o aluno dos cursos da Relações Públicas, inclusive desde antes do ingresso na universidade, sobre a profissão que pretende jogar suas energias, estudando e, depois, despendendo, parte ou toda a sua vida;

11 motivarospais dosalunos, explicitandoIhes o significado do curso que seus filhos estão freqüentando, mas que não sabem explicar o que é e para que serve. Assim, justificando os custos pelos quais estão pagando e por meio do qual esperam, em futuro próximo, ver seus filhos bem situados na vida;

12 deixar cristalino às diversas categorias profissionais e claro à sociedade em geral qual é o ser eo fazer desta profissão, assim a valorizando e permitindo-Ihe uma ideologia quevenhaalheprescrever umasagagloriosa.

\section{O outro quadro de referência}

O quadro de referência, a seguir proposto, paraateoriaepráticadaatividadedeRelações Públicas, situa-se na esfera da política, podendo prover caminhos alternativos para perceber, interpretar eexplicar osfenômenos no sistema organização-públicos. Para tanto, defende a tese de que:

A atividade profissional de Relações Públicas é a gestão da função organizacional política a fim de preservar a missão e os objetivos organizacionais dos interesses e objetivos dos agentes com influência.

Com isto, reforça o princípio, já há muito estabelecido, porém pouco concretizado, na comunidade de Relações Públicas que, na prática, a ação profissional seoperacionaliza por meio de quatro operações:

1 diagnosticar o processo de relação de trocas de interesses político-econômicos no sistema organização-públicos, inserido no contexto dasociedademaior emqueo sistema se encontra;

2 prognosticar, a curto, médio e longo prazos, a resultante do entrechoque da ação organizacional ante as expectativas dos públicosnoâmbito daevolução daconjuntura;

3 assessorar os líderes organizacionais, em especial o líder máximo, prevenindo-os das possíveisocorrências deconflito ecrisese suas causas, apresentando sugestões quanto aosprogramas deação daorganização aserem executados que evitem e/ ou resolvam os impasses;

4 implementar programas planejados e específicos de comunicação com os vários públicos, que venham a explicar, justificar, persuadir ou negociar decisões organizacionais.

Os conhecimentos científicos que ajudam a compreender, prever econtrolar o fenômeno de Relações Públicas estão situados nas Ciências Sociais, dentreestas, em especial, na teoria política, especificamente, na esfera da micropolítica. A consecução dos objetivos organizacionais, certamente, dentro de 
aspectos éticos e estéticos da atividade, somente poderão ser atingidos se a organização, em sua ação e discurso, atuar em base de poder legítima.

Estas premissas, a partir das quais será efetuado um processo de dedução, implicam de maneira direta e imediata:

(a) os objetos materiais da atividade são a organização e seus agentes com influência, designados, até agora, por públicos;

(b) osobjetosformaissão o conflito iminente e a crise provável nas relações de interesses no sistema organização-públicos.

\section{A justificativa}

Justificar esta hipótese, utilizando-se argumentação hipotético-dedutiva, apesar de trabalhosa, não é impossível, em face dos princípiosjáestabelecidosporvárioscientistas cujos trabalhos se encontram na bibliografia dasCiências Sociais, onde, aliás, seencontram muitíssimos mais princípios de Relações Públicas do que nas obras específicas do assunto.

Os obstáculos encontram-se no bloqueio mental na comunidadede Relações Públicas, estabelecido econdicionado pelo paradigma desdehá muito introjetado, o deque Relações Públicas é comunicação. Sem dúvida que também o é. Pode ser entendido por meio de al gumas das teorias de comunicação, porém seu mel hor quadro dereferência para aportar com maior clareza a explicação eas causas do fenômeno de Relações Públicas encontra-se na ciência política, mais precisamente na micropolítica.

Procurei oportunizar arupturado paradigma comunicacional (Simões, 1993), apresentando as primeiras idéias sobre a gestão da função organizacional política, posicionando a comunicação como meio eainformação como matéria-prima, utilizando-se de diversos instrumentos para o exercício do poder, dito deoutro modo a essência coma micropolítica e a aparência com a comunicação. Foi uma primeira tentativa, caracterizada pela apresentação dos conceitos. Agora, tento aprofundar um pouco mais essa visão.

Um primeiro problema para posicionar a atividade de Relações Públicas situada com seus fundamentos científicos na esfera da políticasão as conotaçõesqueo termo política possui. Política, para o homem comum - a maioria dos empresários e governantes o ée mesmo para muitos acadêmicos e alunos universitários, refere-se exclusivamente à esfera da politica partidária. A constatação destefenômeno éfácil. Experimente-sedizer que Relações Públicas refere-se à função política que certamente serão levantadas questõestaiscomo:Quetem RelaçõesPúblicas a ver com os políticos? Como é Relações Públicas para os partidos?

Todavia, não é somente o leigo que não discrimina o conceito. Os cientistas sociais, inclusiveos "politólogos", entendem política como ogoverno da polis, ou seja, a perspectiva macro desta ciência e práxis. Para a maioria, de um modo geral, até o presente momento, política refere-se ao "governo do Estado".

Burns (1961, p. 260) diz que ninguém, nas organizações, sepercebecomo umser político ou atuando politicamente, por existir dois problemas o viés da polis e a conotação pejorativa que o termo política possui, ou seja, o de politicagem, caracterizando as pessoas como carreiristas. Estefenômeno não ocorre somente no Brasil, mas em muitas outrasculturas, imprimindo-lhepreconceitos quanto ao designativo política, prejudicando a compreensão do que se escreve e se fala deste tema. Há, ainda, no Brasil, outro elemento deletério, quando se trata deste termo, éum antigo refrão, introduzido não se sabe por quem, que diz: "Política, futebol e religião não se discutem". Esses aspectos condicionaram o povo brasileiro. Freqüentemente se escuta alguém dizer, nos mais 
diferentes cenários: "Eu não sou político!" Comoqueseescusando depertencer ao grupo dos "políticos", ou melhor, dos "maus políticos". Não percebendo que sempre está em relação política com seus semelhantes, quaisquer que sejam as situações.

A superação deste obstáculo pode ser realizada entendendo-se o significado de política e seu vínculo com o exercício do poder. Deixando-se de lado a tradicional definiçãodepolíticacomoaciênciadoEstado, encontra-se modernamente a concepção segundo Crick e Crick (1987, p.1) de que política é o estudo dos conflitos de interesses e valores que afetam a toda e qualquer sociedade e a maneira de como eles podem ser conciliados. Deduz-se, desta definição, quea política compõe-sedeuma teoriaeuma prática. A teoria explicao processo eaprática, implicando os programas, interfere no processo. Infere-se do fato da presença do conflito, a existência do processo decisório e, daí, também, arelação depoder nosistema. $O$ estudo do sistema político arrola a tomada de decisão, o tomador da decisão eo sujeito das conseqüências da mesma. Petersen (1988, p. 7) relata a noção de ciência política como "ciência do poder" .Corsetti (1988, p. 31), mais enfático, assinala que: A ciência política tem sido o campo fundamental do estudo do poder.

Assiméque, enquanto teoria, a política busca compreender os processos do exercício do poder em sociedade, qualquer que seja seu extensão. $\mathrm{Na}$ prática, busca interferir no processo, no qual ocorrea rel ação de poder, a fim de organizar a sociedade.

É óbvio que se somam a esses problemas o fato de que os cientistas políticos, apesar das inúmeras pesquisas ou, exatamente por isto, tambémnão chegaramaum consenso quanto àdefinição eànatureza do exercício do poder. Pode-secitar, entreeles: Cartwright, D. (1959), Festinger, L. (1961), French, J. e Raven, B. (1965), Varela, J. (1971), Weber, M. (1978), Wrong, D. (1979), Bacharach, S. e Lawler, E.
(1980), Luhmann, N. (1980), Foucault, M. (1980), Mc Carney, J. (1980), Barry, N . (1981), Bobbio, N. (1983), Raven, B. (1975 e 1983), Galbraith, J. (1984), Lukes, S. (1985 e 1986), Burbules, N . (1986), Therborn, G. (1988). Cada umapresenta suateoria, posicionando-seem uma premissa específica e gerando tipologia diferente das dos seus colegas. No entanto, percebe-se, nitidamente, três grandes correntes: a tradicional, para o qual o poder é al go existente, independente da relação; a da relação depoder envolvendo exclusivamente a interação; e a de transação, envolvendo recursosescassosexistentesnasociedade.Esta última escola partedo princípio dequesenão houvesse recursos escassos envolvidos, o ser humano não necessitaria desesubmeter, não necessitaria de proteção. Ou, ao contrário, não buscaria o poder. Ressalva-se que a maioriadessacomunidadeconsiderao poder como não factual, mas resultante da prática social. O poder éal go queseexercenas relações humanas.

Uma premissa: a organização e sua dimensão política

Deduz-se das definições assemelhadas de Parsons (1969, p. 17), deKatz eKahn (1979, p. 31), de Krech, Crutchfield e Ballachey (1969, p. 4) que a organização é constituída por pessoas, ou seja, por indivíduos em seus papés, estruturados em grupos, formando um sistema de ações, mais ou menos concatenado para atingir objetivos. É de sua natureza uma estrutura de comunicação, informação, valores e processo decisório. Ocorre que, normalmente, os objetivos dos indivíduos(João, Maria, Pedro) são diferentes dospapéis (presidente, tesoureiro, porteiro)e dos grupos (Contabilidade, Vendas, Produção). Cadaum desses elementos buscaatingir objetivos que satisfaçam suas necessidades. Assimquea organização apresenta, já em seu âmago, a possibilidade de conflitos.

Infere-se, também, que a organização, como entidade factual, não existe. A organização 
explicita-se por meio de uma estrutura, compreendendo um organograma - o elemento estático, que caracteriza o status de cada membro e também o plano de carreira, portanto a relação de poder entre todos - eo fluxograma - processo dasações concatenadas de cada um dos papéis, operacionalizando o exercício depoder, ou mel hor, ainda, segundo Blumer (1971, p. 20): A essência da organização reside em um processo de ação em marcha, não em uma estrutura postulada de relações. Há um sistema social cuja forma de governo (poder) pode estar centrado numa pessoa, numa diretoria, num partido, na burocracia ou, ainda, numa família.

A argumentação depara-secomumobstáculo quando se busca entender quais sejam os objetivos da organização, que o sistema de papéis deve atingir. Deve-se fazer uma diferenciação entre a missão da organização de seus objetivos. Por missão entende-se o mesmo que Mitzberg (1992, p. 6): A função básica da organização na sociedade, em termos dos bens e serviços que oferece a seus clientes e por objetivos a intenção existente por detrás de cada decisão. Certamente que existem missão e objetivos publicados em esplendorososdocumentos, comafinalidadeexclusiva de torná-los público, enquanto que, na realidade, se persegue outros fins em face da dinâmica do confronto de interesse de cada extrato da organização e, até mesmo, de agentes com infuência externa. Quanto aisto, Silverman (1971, p. 9) argumenta que: Parece duvidosa a legitimidade de conceber uma organização como em busca de uma meta, exceto quando há um consenso entre os membros da mesma sobre os propósitos de sua interação, pois as empresas e outras instituições se caracterizam por tal ausência de consenso.

Se a existência de missão e objetivos claramente definidos ainda não significa o êxito organizacional, pois há inúmeras alternativasparasechegar atéeles, imaginem se eles estão apenas subentendidos ou, até mesmo, inexistentes. Em razão disto, ou seja, das váriasalternativas decomo chegar lá, dos inúmeros interesses existentes no sistema de papéis, a organização torna-se um espaço político. A dinâmica organizacional revela-se uma dinâmica de luta pelo poder. Uma dinâmicaondeumtentainfluenciar aosoutros a fim de que seus interesses, fundados em suas necessidades, sejam atendidos.

A percepção dasorganizaçõescomoentidades políticas não é fenômeno recente e cientistas políticos, entre eles, Weber (1947), Merriam (1950,), Leoni (1957), Burns (1961), March (1962), CyerteMarch (1963), Kaufman (1964), Lawrence e Lorsch (1967), Harvey e Mills (1970), Zaleznik (1970), MarcheSimon (1972), Wamsley e Zald (1973), Pettigrew (1973), Georgiou (1973, p. 291), Patchen (1974), Pfeffer (1973 e 1981), Pfeffer e Salancik (1974) e Mintzberg (1992) não tiveram dúvidas em considerar osprocessosorganizacionaiscomo sendo um dos tipos desistemas políticos. Em destaque nesta afirmativa encontra-se Burns (1961, p. 258):

A tendência de considerar as corporações de algum modo, ou em essência, organizações políticas equivalentes aos Estados, apesar de suas condições reduzidas, tem sido reforçada pelos estudos dos sistemas administrativos, os quais, desde Weber, têm aplicado os mesmos termos, autoridade, legitimidade, dominação, subordinação, etc., para instituições políticas, eclesiásticas, militares e econômicas.

Porém não é somente este autor da comunidade científica sobre as organizações que se podecolocar em destaque. Georgiou (1973, p. 291) também ajuda a colocar o visor sobre o quadro de referência política das organizações:

As organizacões são, efetivamente, um âmbito de atividade política, sem que possuam objetivos por elas mesmas. Existem focos arbitrários de interesses e mercados, cujas estruturas e processos são o resultado de complexas acomodações realizadas por 
agentes sujeitos a uma variedade de incentivos e perseguindo uma diversidade de objetivos.

Outro mais, participando do grupo daqueles quesustentam ser asorganizaçõesumâmbito político é Trindade com seu ponto de vista analítico, exposto em palestra no Curso de Relações Públicas da PUCRS (1974):

Toda organização, seja ela qual for, além dos seus objetivos específicos (econômicos, culturais, religiosos, políticos) é um subsistemasocial no interior dasociedadeglobal. Enquanto subsistema social possui, em seu interior (eu diria, também em seu exterior), relações sociais estáveis (interação entre indivíduos e grupos) e também um tipo particular de relação social que se denomina relação política. Asrelações políticas, portanto, não são de outra natureza quea das relações sociais. N estaperspectiva, as relaçõespolíticas não designam um novo tipo de relação, mas aspectos específicos das relações sociais. Existem relaçõespolíticas esistemas políticos na medida em que existir: a) luta pelo poder; b) tomada de decisão e processo de escolha.

Se tudo isto não é suficiente, para extirpar dúvidas, tem-se, ainda, Iannacone (1991, p, 467), relatando que: $A$ organização deve ser ol hada como um sistema político, isto é, um âmbito onde as relações entre os papéis, os indivíduos e os grupos se encontram em um processo de influência, visando a recursos escassos. Está bem explícito que este autor e Trindade pertencem à escola que percebe a relação política sempre acompanhada de decisões sobre recursos escassos, enquanto queBurnseGeorgiou não declaramesteponto de vista abertamente.

Assim, com essas citações de cientistas profundamente envolvidos com o estudo da política, possivelmente, confirma-seestetipo de relação intrínseco às organizações e da qual participam inúmeros jogadores.

Esses jogadores, até então designados por públicos, têm sido classificados segundo o critério geográfico de internos, externos e mistos, exceção a Matrat (apud Simões, 1993, p. 31) que, já com a visão da relação de poder no sistema organização-públicos, os classificou em públicos com poder de consulta, de decisão, de comportamento e de opinião. Contudo, ambas as tipologias enfrentam al gum tipo de problema de aplicação teórica e de enquadramento de alguns elementos que possuem interesse comum com as organizações. Por exemplo, como enquadrar o presidente da organização? Como enquadrar os bancos, etc.?

Por isto, é possível que se possa adotar um novo designativo, que oferece Mintzberg (1992, p. 24) expondo em sua teoria que a missão da organização e, por conseqüência, a própria organização estão sujeitas a agentes com influência.

Sua obra, apesar de não ter sido escrita sobre Relações Públicas, trata-se de um manual de Relações Públicas. Nela, Mintzberg define agentes com influência: são pessoas, conjunto de pessoas, grupo, inclusive outras organizações que buscam o controle das decisões e ações que toma a empresa. Além disto, os classifica em internos: proprietário, presidente, diretores, chefias, pessoas daatividade fim, pessoal da atividade meio, analistas da estrutura técnica e em externos: acionistas, fornecedores, clientes, sócios, concorrência, sindicatos, mídia, asssociações de profissionais, familiares, amigos, líderes deopinião, órgãos governamentais, instituições financeiras, instituições locais e comunidade.

Prosseguindocomsuateoria, Mintzberg relata que estes agentes podem tomar uma das três opções: calar e obedecer às decisões tomadas (ex: o funcionário que cumpreas ordens sem sequer dar qualquer tipo desugestão), sair do jogo (ex.: o clienteinsatisfeito quenão compra mais e desaparece) elutar antes que se render, também, designado por $V$ oz (ex: todosaqueles que tentam interferir, de uma maneira ou outra, nas decisões organizacionais). A estes, e somente a estes, é que Mintzberg designa 
por públicos.

A visão dasorganizaçõescomoâmbitopolítico onde se defrontam diversos agentes permite que se analise e aborde seus fenômenos e problemas, do ponto de vista das Relações Públicas, segundo o quadro de referência política.

A redução da angular: da macropolítica à micropolítica

Observa-se, analisando-se diversos autores que tratam do tema, que a natureza da micropolítica - quejá não sepodemais negar ser um constructo na teoria política - possui duas óticas, que, se complementam, antes que divergem.

Aborda-se uma das óticas por meio de um raciocínio lógico bastante simples quanto ao artifício do paralelismo entre Economia e Política. Se a comunidade de cientistas da Economia (cujo outro lado da moeda é a Política) concorda com a divisão desta área do conhecimento em macro emicroeconomia, então, a comunidade da Ciência Política também há de convir que a Ciência Política possaser subdivididaemdoisgrandesramos: a macro e a micropolítica. A macropolítica trata com grandes agregados e estatísticas quepodem, ou não, representar eventos reais enquanto que a micropolítica, por sua vez, trata com escolhas quesão feitas por pessoas, buscando atingir seus propósitos.

Encontra-seesta ótica na esfera da Educação, encabeçada por lannaccone(1975e1991) que, conforme relatam Marshall e Scribner (1991, p.347), cunhou o termo micropolítica da educação, ao final da decada de 60, referindosea estedesi gnativo como o estudo ea prática da relação de poder dentro e ao entorno das escolas, grupos e famílias. Participam com Iannaccone, inúmeros outros autores, que o seguiram e que relataram várias pesquisas, sedimentando esta área de estudo. Dentre eles: Burns(1961), Kessel (1970), Pfeffer (1973),
Hoyle(1982e1985) Greentein ePolsby (1975), Blecher e White (1979), Burbules (1986), Ball (1987), Pirie (1988), Burlingame (1988), Marshall e Scribner (1991), Willover (1991), Everhart (1991), Blase (1991), Ball e Bowe (1991), Corbett (1991), Marshall (1991), Greenfield (1991), Bloome e Willett (1991), Lazega (1992).

Em especial, entre aqueles cujas idéias dão suporte para que o processo de Relações Públicas contenha, em sua essência, os aspectos políticos e na sua aparência a comunicação, encontra-seBall $(1987,249)$, ao incluir, em sua obra, um título e espaço para as Relações Públicas das Escolas, total e diretamente correlacionados com o objeto de estudo contido em sua obra. Contudo, toda pessoa quetiver noção teórica sobre Relações Públicas, aoterminar aleitura da obra deBall, resultado deuma pesquisa participante, com certeza dirá que todo seu conteúdo (e não somente seu capítulo específico) tem tudo a ver com a teoria e a prática da atividade de Relações Públicas no âmbito das escolas.

A outraperspectiva, focada por Pirie(1988, p. 127), a sugestão é que há uma 'micropolítica' assim como há uma microeconomia. Enquadramicropolíticana dimensão do Estadoede outras organizações, mas, como abordagem diferentedamacropolítica, propondo-acomo aanáliseetratamento dosproblemaspolíticos, especificando osdiversosgruposdeinteresses e jamais em ação global e considerando-a mais adequada do que a macropolítica para administrar arelação depoder entreas partes envolvidas.

Esta angular, quenão envolveo tamanho dos espaços onde o fenômeno ocorre, percebe a necessidade da rel ação de poder ser segmentadaeassimtratadapelos diversossegmentos de acordo com os diversos grupos de interesses com os quais o governo ou as organizações se relacionam.

Assim se expressa Pirie (1988, p. 127), comparando as duas esferas da política: 
“Micropolítica, por outro lado, envolve a formulação deprogramas deação que reconhecem as descobertas dosteóricos da escolha pública ${ }^{1}$ e seu uso para redirecionar o comportamento de indivíduos e grupos envolvidos."

A teoria da escolha pública trata a atividade política como se fosse econômica. Inclui o poder, como uma vantagem, no princípio de que no mercado da economia privada as pessoas negociam vantagens todo dia, desistindo daquilo quelhes pareceter menos valor por aquelas que julgam de maior valia. Essa teoria não teve plena aceitação entre os estudiosos do tema. Foucault (1979, p. XIV), por exemplo, rejeita a concepção de poder inspirada pelo modelo econômico, que considera o poder como uma mercadoria. Para ele e muitos outros, o poder não é uma mercadoria, ou seja, um objeto.

Se este princípio, por um lado não obteve total êxito no campo da política, por outro desenvolveu-se excepcionalmente no ninho do marketing, possibilitando formar um conjunto binário - o marketing econômico eo marketing político e daí uma série de programas de ação na área. A crítica que arrisco fazer éa de que a ótica de Buchanam e Tullock, ao criar o mercado do poder, fez uma circuncisão na teoria do poder por recursos escassos. Descaracterizou poder da economia, e talvez aqui esteja sua miopia.

Nem tudo foi colocado marginalmentenesta teoria. Há um outro princípio que está livre desta polêmica. Trata-se de que as minorias podemser maisprontamentebeneficiadas do que a maioria. Esta parte da teoria é que a micropolítica se apossou e utiliza em seu razoado científico e prático.

Retornandoàexplanaçãosobreamicropolítica deve-se afirmar que Pirie não se encontra isoladoemsuaassertiva. A companha-o vários outros cientistas. A penas como exemplo temseSorauf, citado por Petersen (1988, p. 13), ao dizer que:
“A ciência política tem que possuir a visão micro (análisedo comportamento político, individual e de pequenos grupos, de atitudes, de aspirações, objetivos, metas, fins, ações políticas e suas influências no funcionamento do sistema) e uma visão macro (análise da totalidade do sistema político, enfocando as relações interinstitucionais em nível nacional einternacional)."

Finalmente, sem esgotar totalmente o tema, pode-se concluir este tópico com Willower (1991, p. 442):

“Embora micropolítica seja definida de diversas maneiras por diferentes autores, ela, geralmente, ocupa-se com fenômenos, taiscomo, poder, influência econtroleentreindivíduos egrupos em um contexto social, amiúde em uma organização."

Estastrêscitaçõessobremacroemicropolítica, apesar de enfoques diferentes, permitem deduzir que de fato, na dimensão de um terceiro nível de abstração, se pode compreender aexistência deuma prática do exercício do poder, logo depolítica, na dimensão entre pessoas, grupos e organizações, na tentativa de organizar esses tipos de sociedade.

Relações Públicas e Micropolítica: processos e programas

Cabeagora comparar as esferas das Relações Públicas e da Micropolítica everificar sesão, total ou, pelo menos, parcialmente sobrepostas e que ambas possuem e se expressam por meio de processos e programas bastante semel hantes, senão comuns.

Entenda-se por processo a dinâmica do fenômeno, contendo todas as suas variáveis constantes que levam a um determinado resultado. Enquanto que, por programas, se consideram as ações, contendo variáveis intervenientes, colocadas consciente e 
intencionalmente pelo profissional, na busca do controledo fenômeno, visando a objetivos bemdeterminados. Conhecer o processo exige a análise. Implantar programas implica optar por abordagem e técnicas.

Talvez seja interessante iniciar este estudo comparativo, realizando uma arqueologia na busca dos princípios básicos das Relações Públicas e evidenciar a proposição de que Relações Públicas é, antes detudo, conforme já dizia na década de 60 Canfield (1961, p. 5): São uma filosofia da administração, uma atitude de espírito, que situa os interesses das pessoas acima de todos os assuntos ligados à direção de indústrias ou organizações de serviço. N o sentindo de que uma organização para possuir bom relacionamento público deve conter em seu âmago um egoísmo esclarecido queleveem conta, antes detudo, os interesses dos seus públicos. Se assim o fizer terá um excelente retorno para seus objetivosemetas. Esteprincípioéencontrado, parcialmente, noslogan tradicional: “O cliente tem razão".

Ora, Pirie (1988, p. 129) afirma: Ela [micropolítica] reconhece a reivindicação dos grupos, porém sem conceder, por conceder, busca edificar políticas que ofereçam algo em troca pelas perdas que os grupos sofreram. Isto deveriaser realizado por meio denegociações, como propõem Susskind e Field em toda sua obra (1997). A coincidência é cristalina. A continuação desteestudo comparativo requer o retorno à definição operacional de Relações Públicas, anteriormentedescrita, ea dedução de que as duas primeiras operações diagnosticar e prognosticar - dizem respeito à análise do sistema, a terceira refere-se à colocação em prática de programas de ação da organização. À quarta e última, cabe o planejamento ea implementação do discurso da organização, por meio de técnicas de informação e comunicação.

Veja-se agora o que diz Pirie (1988, p. 130):

“[Micropolítica] começa com análise detalhada do status quo, das várias vantagens e benefícios usufruídos, da natureza dos grupos de interesses envolvidosedo poder edas pressões de que são capazes de desenvolver. A seguir, procedea construção de programas de ação que oferecerão trocas em benefícios, alterarãoa estruturadepoder entreosdiferentesgruposeimplantarão incentivos para levar indivíduos e grupos a aceitarem circunstâncias que levam a uma diminuição a longo prazo datransferências deganhos eà redução na proporção de bens e serviços fornecidospel osetor do Estado[N o caso das Relações Públicas, pela organização]."

Possivelmente, não satisfeito com os resultados que esta afirmação poderia causar em seusleitores, Pirie(1988, p. 282) vol taaotema, dizo anterior deoutramaneira, especificando um pouco mais aquela proposição, mas sem, no entanto, modificar suaessência, senãovejase:
“[Micropolítica] identifica os grupos de interesses e coloca em evidência o que elespercebemser suasvantagensecomo eles irão usar o sistema para defendê- las. Então, sugerecaminhosqueassegu- rarão a cooperação daquel es grupos ao fazer uma oferta mais atrativa a cada um deles. Está, igualmente, capaz de previnir os líderes (da organização) da possibilidade de alguns perigos que as iniciativas propostas encontrarão e a sugerir meios para torná-los mais fácil de superação."

Ora, todas estas ações deanálise, diagnóstico, prognóstico e implantação de políticas, correspondem exatamente às três primeiras operações dadefiniçãooperacional.É possível que algo cause espanto a um leitor menos avisado, o qual dirá, segundo sua ótica, quea atividade de Relações Públicas não constrói programas de ação com as finalidades acima descritas. 
É possível quealgunsou muitosprofissionais não tenham tido esta experiência. Porém isto não significa que $a$ atividade se exima da função de dar pareceres para que o centro de poder organizacional implante políticas que venham a provocar todos esses resultados. Aliás, épor estemotivo queo profissional de Relações Públicas deve estar posicionado hierárquica e diretamente ao presidente da organização.

Mesmo porque, utilizando-se ainda de Pirie (1988, p. 226), será mais fácil mudar atitudes após as políticas terem sido modificadas, do que antes. É muito mais provável que as pessoas percebam os benefícios práticos quando eles estão presentes do que quando não estão. Assim atuando, antes a ação e depois o discurso, os dois componentes do processo de Relações Públicas, certamente, que as relações entre a organização e seus públicos ficarão em melhor nível.

Comparando, novamente, os dois processos, o de Relações Públicas e o de Micropolítica, pode-se inferir queos antigos clichês: fazer o melhor possível e depois informar e 90\% R (real izar bem) e 10\% P (tornar público) estão enquadrados na proposição anterior dePirie. O significado de em primeiro lugar, arrumar a casa e, depois, divulgar possui bases concretas na teoria da micropolítica.

Seassim não o fosse, como sepoderia negar a importância ao papel do ombudsman? Além disso, de que outra maneira se justificaria o ditado de que em Relações Públicas "a reclamação éum limão do qual se podefazer a mel hor limonada", quer seja, utilizando-se o bal cão ou a tecnol ogia do Tel efone A berto?

Outros pontos podem ser levantados, sebem quediscutir todos implicaria um compêndio sobre o tema e deturparia a função deste artigo. Contudo, da análise comparativa das duas óticas sobre o termo micropolítica se pode extrair algumas conclusões. Enquanto umautilizacomo critério aanalogiaeo espaço político, a outra utiliza-setambém do critério de analogia, mas reduz a angular do global para as partes, especificamente para os interesses das pessoas e dos grupos.

Pode-se afirmar, sem possibilidade de erro, quea micropolítica, além detratar da relação política entredoisou mais elementos, anal isa e interfere na relação de maneira específica com cada grupo de interesse, jamais atua sobre o global e toma decisões que afetem a todos ao mesmo tempo. Isto porqu, vai ao encontro do princípio deque os interesses de cada grupo normal mente são contraditórios a um ou mais interesses dos outros grupos envolvidoscomaorganização. Tem-seainda, mais uma vez, o apoio em Pirie (1988, P.210): A micropolítica reconhece o mérito de segmentar essas classes em frações menores, a fim de lidar com elas separadamente.

Este princípio, quando se trata de aplicar técnicas, deve ser levado em total consideração, sobre este ponto nos acode Pirie (1988, p.203) ao dizer que: As técnicas com as quais a micropolítica trabalha, em determinada área, não podem simplesmente ser aplicadas a outra, sem antes examinar as diferenças entre ambas.

Ora, essa afirmação vai diretamente ao encontro dad efiniçãooperacional deRelações Públicas, poiséexatamenteo quea tecnologia da atividadepropõe: diagnosticar eprognosticar a relação entre a organização e seus públicos, enfocando-os separadamente, verificando seus interesses e a sua relação comatrajetóriadaorganização. A téesteponto fica-se com a análise do fenômeno. A intervenção no mesmo ocorre na terceira operação, quando é dito que ao profissional cabe assessorar a liderança organizacional quanto às políticas deação. A qui, então entra a técnica da micropolítica, que éimplantada não pelo profissional de Relações Públicas, mas pelo líder máximo da organização, ou seja, aquele que detém o poder de implementar os programas deação. A micropolítica vem confirmar que os programas devem ser específicos a cada público. 
Pirie (1988 p. 261) diz:

"Busca influenciar decisões nas margens, no ponto onde as pessoas formam a concepção que uma escolha dá-Ihes mais benefícios que outras. Promove e encoraja essas trocas. Tenta ampliar o raio de ação no qual elas podem operar e coordenar as circunstâncias para fazer com que alguns resultados visivelmente preferíveis a outros."

Contudo, a estratégia da micropolítica, coadunada perfeitamente com a teoria das transações, é impulsionada pelo motor da troca. Se as pessoas não podem fazer trocas, elas não podem optar por alternativas mais atrativas. Isto explica um dos problemas do mercado de trabal ho da atividade e também do enfoque que ela toma nos países e nas organizações cuja cultura política é centralizadora, onde existe monopólio e onde as pessoaseosgruposnadapossuem paratrocar. Onde qualquer ação política dos públicos implica sempre perda para os mesmos. Onde os grupos não possuem força de troca.

Portanto, maisumargumento para explicar o porquê do restrito mercado para a profissão deRelaçõesPúblicasnoBrasil ou em qual quer outro país onde predomina uma população desorganizada, sem recursos para pressionar as organizações. As organizações não são forçadasatrocar. Elasrestrigem-seao discurso panfletário e retórico, no seu sentido pejorativo.

Esta idéia, também, vem a resolver antigo impasse existente em nossa área: 0 pinião pública ou 0 pinião dos públicos, estabelecendo um critério para que se possa optar pelasegunda afirmativa, istoé, a Opinião dos Públicos. Por outro lado, apóia a classificação dos públicos feita por Mattar, não os considerando somenteem posição geográfica deinternos, mistoseexternos, masem relação aotipo depoder quelheséconferido eàteoria de Mintzberg que os denomina de agentes cominfluência. Ademais, vem confirmar que nos pareceres dados ao líder da organização, sobreaimplementação deprogramas deação ${ }^{2}$ peloprofissional deRelaçõesPúblicas, devem ser propostas soluções particulares a cada público.

A proposta de um programa de ação para atender as reivindicações de uma maneira global, afetando todos os públicos globalmente, somentedeveráser realizadaemcasos excepcionais, que, provavelmente, jamais ocorrerão. Daí, decorretambémadificuldade deaorganização possuir uminformativoque contenha mensagens adequadas a todos os seus públicos.

Por isto, é adequado repetir Pirie (1988, p. 283):
"As bases da estratégia da micropolítica estão em lidar com os grupos de interesses e reestruturar as circuns- tâncias de tal maneira que se torne vantajoso para os grupos optarem pelo curso submetido à apreciação pelos elaboradores de programas de ação."

Transladando esteprincípio paraa esfera das Relações Públicas, pode-se identificar a importância da modificação dos programas de ação organizacionais a fim de integrar os interesses com os seus públicos.

Ficar somente no discurso, no sentido de explicar, justificar, prometer, não resolve o problemadeRelaçõesPúblicas. Etioni (1978, p. 72) já dizia que “....as diferenças de interesse econômico e de posição de poder não se desfazem pela comunicação".

Daí asvantagensdamicropolítica, Pirie(1988, p. 283):

"O enfoque micropolítico tem duas vantagens muito importantes sobre 0 estilo convencional de política (a maioria). Ele resolve problemas e é atrativo aos líderes políticos." 
A pesar detudo isto ou, exatamente, por tudo isto, proponho à comunidade de Relações Públicas a apropriação deste termo também, paranossaesfera, poisadimensão da política, especificamente da micropolítica, tanto na teoria como na práxis, está bem caracterizada nosfenômenos, intraeinterorganizaçõescom os seus agentes com influência.

\section{E a comunicação, como fica?}

Os limites entre comunicação e exercício de poder são muito tênues, por vezes até se confundem. As razões deste fenômeno, possivel mente, têm suas origens no diversificado uso do termo comunicação na linguagem do senso comum e no fato da comunidade científica não ter chegado a um acordo quanto à definição do conceito e, freqüentemente, fazer umasociologiadacomunicação, discorrendo sobre as implicações do conceito na sociedade e na cultura, sem defini-lo ecaracterizar sua natureza, quando deveria fazer a ciência particular da comunicação, aprofundando estudos sobre sua definição e sua natureza.

A utilização do conceito comunicação éfeita, por vezes em um mesmo texto, com significados diferentes, quer seja na linguagem do senso comum, o que é al go justificável, mas, também, nalinguagem científica, quemerece pelo menosumaanálisecrítica, paranão dizer queéimperdoável. Por vezes, ésinônimo de informar. Por exemplo: "O Instituto de meteorologia comunicou que amanhã choverá". Assim sendo, cada um utilizará proteção contra a chuva se desejar epuder. $O$ exercício de poder é do estilo laissez-faire. Em outro exemplo, tal como " Comuniquem aos funcionários que a partir de amanhã não ganharãohoras-extras", contémaperspectiva deordenar, caracterizando umtipo derelação de poder autocrático. Outras, referem-se a persuadir. Como exemplo: "Esta peça publicitária comunica bem, poisestálevando os clientes às compras". Outras tantas vezes, corresponde, também, ao sentido de dial ogar, deação comum, encontrado na teoria deação comunicativa de Habermas (1987), na teoria existencialista de comunicação, no conceito decondutacomunicativadeMaturana(1984), no sentido de processo e resultante, como propõemKatz eKahn (1979), eainda, nalinha doInteracionismosimbólico deBlumer (1969). A relação democrática encontraria, neste modelo, suaforçamáximadeexpressão, sendo apráticadanegociação ganha-ganhaomelhor exemplo.

Dance (1970) relata sua pesquisa sobre os conceitosedefinições dotermo comunicação, tendo encontrado 95 exemplos, reduzindo-os a 15 categorias, segundo al guns critérios de classificação.

Por isto, ou, exatamente, como causa disto, há defini ções de comunicação e de exercício de poder que explicitam o mesmo fenômeno. Veja-se, Berlo (1970, p. 20 ) propõe: Em suma, nós nos comunicamos para influenciar - para afetar com intenção. Por sua vez, Miller (1966, p. 92), expressa seu conceito de comunicação da seguinte maneira:
“Na sua essência, comunicação tem como seu interesse central aquelas situações comportamentais nas quais uma fonte transmite uma mensagem para um (uns) receptor (es) com a intenção consciente de afetar o compor- tamento deste (s)."

Enquanto que as definições relatadas por cientistas da rel ação de poder , Weber (1947), Parsons (1969), Wrong (1979), Raven (1965), entre muitíssimos outros, poderiam ser sintetizadas da seguinte maneira: Exercício de poder é a probabilidade de A decidir ou influenciar a decisão de $B$, em processo de troca, envolvendo recursos escassos. Ou, dito deoutra maneira, segundo Mitzberg (1992, p. 5): É a capacidade (de A) de afetar (causar efeito no) o comportamento das organizações (de B). Há, ainda, a perspectiva de Semama (1981, p. 18): N enhuma comunicação é, na sua filogênese, diversa de uma comunicação 
imperativa.

Ora, sedoisconceitossão iguaisaumterceiro, logo são iguais entre si. Isto é o que se pode concluir, comparando estas definições de comunicaçãoedeexercício depoder. Portanto, ateoriamaisadequadatal vez sejaa deSchacter (1951, p. 191): Comunicação é o mecanismo pelo qual o poder é exercido. Esta definição chama a atenção das dificuldades de tratar com os dois temas e ainda, que é impossível isolá-los na prática da vida. O exercício do poder, a prática da política, éimpossível sem umprocesso decomunicação, sendo, portanto, estes dois elementos, os dois lados de uma mesma moeda. Daí a dificuldadedeperceber ou destacar um do outro como ocorrenaquelas figuras da moça e da velha e do copo e duas caras estudados na teoria da percepção.

Se a atividade de Relações Públicas se apresenta realizando somente o discurso da organização, envolvendo o ser humano para que ele, inconsciente, pois "a batalha das idéias" ocorre em nível das generalidades, cedaseusrecursos (direito ao mel hor produto, ao perfeitoatendimento) estáusurpandoesses direitos, utilizando-se do ser humano inapropriadamente e, portanto, sendo antiética. Quanto a isto, tem-se Burns (1961, p.278) a alertar:

“O compromisso político para uma pessoa ou para um agrupamento é um abandono doexercício deindependência de um atributo individual - o direito de voto, possessão de informações, poder persuasório, capacidade de luta ou, ainda, controlederecursosposteriores."

Daí o porquê da informação ser um dos elementos básicos do processo e dos programas. É ela que possibilitará o ser humano a perceber o mundo em que está envolvido ea criar um nova relação com êle.

A o final, esta tese propõe que o exercício de poder é o fim eo processo de comunicação é o meio. O exercício de poder se caracterizará em autocrático, persuasivo, democrático ou laissez-faire de acordo com o tipo de processo de comunicação utilizado.

\section{A próxima premissa}

É de praxe terminar um artigo com uma conclusão. N ão farei isto, poistoda ateseaqui relatada não significa uma conclusão, mas somente uma nova premissa para o estudo e a compreensão da atividade de Relações Públicas. Assim sendo, não encerra um pensamento, mas o abre para discussão e falseamento, única maneira de se realizar ciência. É bem possível que uma das poucas coisas que a comunidade acadêmica de Relações Públicas possui em consenso é de que a atividade necessita de uma teoria que dê suporte a sua tecnologia de ação e à utilização de suas técni cas einstrumentos de exercício de poder e comunicação.

Todavia coloco a última justificativa do por que apropriar-se do quadro de referência política para as Relações Públicas - teoria e práxis:

AsRelaçõesPúblicas(teoria, tecnologia, estratégia e técnicas) referem-se ao sistema organização-públicos.

A organização possui em sua estrutura hierarquia, autoridade, subordinação e processo decisório.

- Os públicos fazem trocas com a organização e possuem, neste processo, interesses namaioriadas vezes divergentes daquel esda organização.

- Os públicos, enquanto sujeitos, nada farão, mas na primeira oportunidade desejarão ser cidadãos e influenciar os objetivos organizacionais.

- $\quad$ A organização almeja a autonomia.

O conflito no sistema é iminente e a 
crise, uma probabilidade.

- A informação éutilizada para mel horar o processo decisório de ambas as partes.

- Os problemas não são resolvidos exclusivamente, ou quasenada, pela comunicação, a não ser quando ocorre negociação. Aí, então, há trocas e compensações por perdas.

Por fim, por tudo isto, o perfil do profissional de Relações Públicas jamais poderia ser o de um tarefeiro, mas, ao contrário, o deum hábil estrategista político.

O trabalho que se tem pela frente é árduo, principalment, para muitos e novos cientistas, jamais para um pensador isolado. A ciênciaétrabal ho social, isto é, degrupo, a criticar vel has hipóteses ea criar novas teorias. Esses cientistas, em tese, deverão compor dois grupos, diferentes, porém complementares. Em primeiro lugar, sem significar valor de importância, aqueles envolvidos com a pesquisa básica, não preocupados, em primeira instância, com a aplicação imediata dos conhecimentos gerados. O outro grupo, enfronhado com a ciência aplicada, produzindo conhecimentos a fim de atingir determinadosedefinitivosfinsoperacionais. Os primeiros, pelo menos na data atual, são figuras raras na comunidade de Relações Públicas. Os outros, se existentes, são pouco conhecidos, poisquasenada têm relatado aos seus pares.

\section{O desafio é para todos.}

\section{Notas}

1 VeraobradejamesBuchanam-PrêmioN obel deEconomia, 1986 - que juntamente com o professor Gordon Tullock e outros desenvolveram a Teoria da Escolha Pública.

20 termo programas de acão estásendo sempreempregado como tradução do termo em inglês policy.

\section{Referências}

BACHARACH, Peter $\&$ LAWLER, E. Power and Politics in Organizations. San Francisco: Jossey-Bass, 1980.

BALL, Stephen. The M icropolitics of the School: Toward a theory of school organization. London: Metheun, 1990.

BALL, Stephen. \& BOWE, R. "Micropolitics of Radical Change: Budgets, Management, and Control in British Schools". In: BLASE, J. (Ed), The Politics of Life in Schools. London: Sage, (19-45), 1991.

BARRY, N. An Introduction to M odern Political Theory. London: MacMillan, 1981.

BERLO, David K. Teoria da Comunicação. Rio de Janeiro: Fundo de Cultura, 1970

BLASE, J. "The Micropolitical Perspective". In BLASE, J. (Ed). The Political of Life in Schools: Power, Conflict and Cooperation, London: Sage, (1-18), 1991.

BLECHER, Marc J. \& WHITE, Gordon. Micropolitics in contemporary Chine: a technical unit during and after the cultural revolution. White Plans, New York: M. E. Sharpe, 1979.

BLOOME, D. \& WILLETT, J. "Towards a Micropolitics of Classroom Interaction". In: BLASE, J. The Political of Life in Schools. (207-236), 1991.

BLUMER, Herbert. Symbolic Interactionism: perspective and method. Englewood Cliffs: Prentice-Hall, 1969.

BLUMER,H. "Sociological implications of thethought of George Herbert Mead". In: COLIN, B.R. et al. (eds) School and Society. London: Open University, 1971.

BOBBI0, Norberto, MATTEUCI, Nicola e PASQUINO, Gianfranco. Dicionário de Política. Brasília, Universidade de Braślia, 1986.

BURBULES, Nicholas C. "A Theory of Power in Educacion". Education Theory, Spring, 36 (2), 95-114. 1986.

BURLINGAME, M. "Review of the micropolitics of the school: Toward a theory of school organization". Journal of Curriculum Studies, 20, 281-283, 1988. 
BURNS,T. "Micropolitics: Mechanisms of Institutional Change". Administration Science Quarterly, 6, 267-281, 1961.

CANFIELD, Bertrand R. Relaçōes Públicas: Princípios, casos e problemas. São Paulo: Pioneira, 1961.

CARTWRIGHT, D. Studies in Social Power. Ann Arbor: The University of Michigan, 1959.

CRICK, Bernard \& CRICK, Tom. What is Politics? London: Edward Arnold, 1987.

CORBETT, H. D. "Community Influence and School Micropolitics: A Case Example". In: BLASE, J. (Ed). The Politics of Life in Schools, London: Sage, (73-95), 1991.

CORSETTI, Eduardo. "Poder epoder político". In: PETERSEN, Aurea et al. Ciência Política: textos introdutórios. Porto Alegre: Mundo Jovem, 1988.

CYERT, R.M.,\& MARCH, J. G. A Behavioral Theory of the Firm. Englewood Cliffs, N.J.: Prentice Hall, 1963.

DANCE, F.E.X. "The Concept of Communication". In: Journal of Communication. Vol 20, 201-210, 1970.

ETZIONI, Amitai. Organizaçōes M odernas. São Paulo: Pioneira, 1978.

EVERHART, R. B. "Unraveling micropolitical mystiques: Some Methodological Opportunities". Education and Urban Society, 23 (4), 455-464, 1991

FESTINGER, Leon. A Theory of Cognitive D issonance. Stanford: Stanford University Press, 1957.

FOUCAULT, Michel. Microfísica do poder. Rio de Janeiro: Graal, 1971.

FOUCAULT, Michel. Power and Knowledge. New York: Pantheon, 1980.

FRENCH, J. \& RAVEN, B. "The Bases of Social Power". In D. Cartwright (Ed) Studies in Social Power. Ann Arbor: The University of Michigan, 1959.

GALBRAITH, John. Anatomia do poder. São Paulo: Pioneira, 1984.

GEORGIOU, Petro. "Goal Paradigm and Notes Towards a
Counter Paradigm". Administrative Science Quarterly, Vol. 18, 291-310, 1973.

GREENFIELD,Jr. W. D. "The Micropolitics of Leadership in an Urban Elementary School". In: BLASE, J. The Political of Life in Schools, London: Sage, (161-184), 1991.

GREENSTEIN, Fred I. \& POLSBY, Nelson W. Micropolitical Theory. Reading, Mass: Addison-Wesley, 1975.

HABERMAS, Jüergen. Teoria de la acción comunicativa. Barcelona: Taurus, 1987.

HARVEY, E. \& MILLS, R. “Patterns of Organization A daptation: A Political Perspective". In: Mayer, Zald (ed) Power in Organizations. Nashville, Tenn.: Vanderbilt University Press, 181-213, 1970.

HOYLE, E. "Micropolitics of Educational Organization". Educational Management and Administration, 10, 87-98, 1982

HOYLE, E. "Educational organizations: Micropolitics". In HUSEN, T. \& POSTLETHWAITE, T. N. (Eds). The International Encyclopedia of Education Research and Studies, 36 (2), 95-114, 1985.

IANNACCONE, L. Education policy systems: A study guide for educational administrators. Fort Lauderdale, FL: Nova University, 1975.

IANNACCONE, Lawrence. "Micropolitis of Education: What and Why". Education and U rban Society, Vol. 23, no 4, August, 465-471, 1991.

KATZ, Daniel e KAHN, Robert. Psicologia social das organizaçōes. São Paulo: Atlas, 1979.

KAUFMAN, H. "Organization Theory and Political Theory", The American Political Science Review, Vol. 58, № 1, 5-14, 1964.

KESSEL, J. H. M icropolitics, Individual and Group Level Concepts. New York: Holt, Rinehart and Winston, 1970.

KRECH, D.; CRUCHFIELD, R. e BALLACHEY, E. 0 indivíduo na sociedade. São Paulo: Pioneira, 1969.

LAWRENCE, Paul R. \& LORSCH, Jay W. Organization and 
Enviroment. Boston: Harvard Press, 1967.

LAZEGA, E. The micropolitics of knowledge: communication and indirect control in work groups. New York: A. de Gruyter, 1992.

LEONI,Leoni. "Themeaning of 'Political', inPolitical Decisions". Political Studies, 5, 239 -245, 1957.

LUHMANN, Niklas. Legitimação pelo procedimento. Brasília: Universidade de Braślila, 1980.

LUKES, Steven. El poder: un enfoque radical. México: Siglo Veintiuno, 1985.

LUKES, Steven. (Ed). Power. Oxford: Basil Blackweel, 1986.

MARCH, J. G., "The Business Firm as a Political Coalition", Journal of Politics, Vol. 24, 662-678, 1962.

MARCH, James G. eSIMON, Herbert A. Teoria das organizaçōes. Rio de Janeiro: FGV, 1972.

MARSHALL, C. "The Chasm Between Administrator and Teacher Cultures: A Micropolitical Puzzle". In: BLASE, J. The Politics of Life in Schools, (139-160), 1991.

MARSHALL, C. \& SCRIBNER, J. D. "'It's all political': Inquiry Into the Micropolitics of Education". Education and Urban Society, 23 (4), 347-355. 1991.

MATURANA, Humberto \& VARELA, Francisco. El árbol del conocimiento. Santiago: Universitária, 1984

McCORNEY, J. The Real World of Ideology. Sussex: Harvester, 1980

MERRIAM, Charles E. Political Power. Glencoe, III: Free Press, 1950.

MILLER,GeraldH. "Ondefining communication:anotherstab", Journal of Communication, vol.16, 88-98, 1966.

MINTZBERG, Henry. El poder en la organización. Barcelona: Ariel Economia, 1992

OAKESHOTT, Michael. Political Education. Cambridge: Cambridge Academic Press, 1951.

PARSONS, Talcott. Structure and process in modern societies.
New York: The Free Press, 1969.

PATCHEN, M. "The Locus and Basis of Influence on Organizational Decisions", Organizational Behavior and Human Performance, Vol. 11, 195-221, 1974.

PETERSEN, Aurea. Ciência Política: textos introdutórios. Porto Alegre: Mundo Jovem, 1988.

PETTIGREW, A. M. The Politics of Organizational Decision Making. London: Tavistock, 1973.

PFEFFER, J. "The micropolitics of organizations". In: MEYER, M.W. et al. (Eds) Enviromments and Organizations. San Francisco: Jossey-Bass, 1973.

PFEFFER, J. \& SALANCIK, G.R. "Organizational Decision Making as a Political Process: The Case of a University Budget". A dministrative Science Quarterly, Vol. 19, no 2, 135-151, 1974.

PFEFFER, J. Power in Organizations. Marshfield, MA: Pitman, 1981

PIRIE, Madsen. M icropolitics: The Creation of Successful Policy. Andershot, Hants: Wildwood House, 1988.

RAVEN, Bertram. "Social Influence and Power". In: Steiner, D. \& Fishbein, M. (Eds) Current Studies in Social Psychology. New York: Holt, Rinehart, Winston, 1975.

RAVEN, Bertram. "Interpersonal Influence and Social Power". In: Raven, Bertram. \& Rubin, Jeffrey. (Eds). Social Psychology. New York: John Wiley, 1983.

SCHACTER, S. "Deviation, rejection, and communication". Journal of Abnormal and Social Psychology, vol. 16, 190207, 1951.

SEMAMA, Paolo. Linguagem e Poder. Brasilia: Universidade de Braślia, 1981.

SILVERMAN, D. The Theory of Organizations. London: Heinemann, 1970.

SIMÕES, Roberto P. Relações Públicas: Função política. São Paulo: Summus, 1993

SORAUF, Francis J. Iniciação ao estudo da ciência política. Rio 
de Janeiro: Zahar, 1967

SUSSKIND, Lawrence \& FIELD, Patrick. Em crise com a opinião pública. São Paulo: Futura, 1997.

THERBORN, G. The Ideology of Power and the Power of Ideology. London: Verso, 1988.

TRINDADE, Helgio. "As ciências políticas nas Relações Públicas". In Anais do 10 Ciclo de Integração de Relações Públicas. Porto Alegre: PUCRS, 1974

VARELA, J. Psychological Solutions to Social Problems. New York: A cademic Press, 1986.

WAMSLEY, G. L.,\& ZALD, M.N. The Political Economy of Public Organizations. Lexington, Mass.: Heath Co, 1973.

WEBER, Max. The Theory of Social and Economic Organization. New York: Free Press, 1947.

WEBER, Max. Economy and Society: An Outline of Interpretive Sociology. Berkeley: University of California Press, 1978.

WILLOWER, Donald. "Micropolitics and Sociology of School Organizations". Education and U rban Society, Vol. 23, № 4, August, 442-454, 1991.

WRONG, Dennis. Power: Its Forms, Bases and Uses. Oxford: Basil Blackwell, 1979.

ZALEZNIK, A. "Power and Politics in Organizational Life", Harward Business Review, Vol. 48, no 3, 47-60, 1970. 